\title{
Review of: "Rootstock effects on scion gene expression in maritime pine"
}

\author{
Rafael Cañas ${ }^{1}$ \\ 1 Universidad de Málaga
}

Potential competing interests: The author(s) declared that no potential competing interests exist.

This article is a good transcriptomic resource for researchers in gymnosperms, especially in conifers, in relation to drought stress response. The authors described the effect of drought-resistant and -sensitive genotypes in four graft-type constructions in maritime pine. This is because climatic change is increasing drought periods in the Mediterranean basin, which could affect their forests. The propagation of selected conifer genotypes, including maritime pine, is very difficult and grafting can be a good alternative to propagate and improve tree responses to environment. However, this has not been very used in conifers, thus, this article is a valuable source of information to compare transcriptomic response of conifers to graft in comparison to angiosperms.

In this work, the RNA-seq analysis was only made over needles, which highlights the rootstock influence over scion. This is interesting since it implies the exchange, and even a crosstalk, of different kind of signals (hormones, peptides, transcripts...) between the rootstock and the scion. This election gives a partial view of the grafts with no information about the rootstocks. However, the economic cost of a deep transcriptomic analysis must be considered in complex experiment such as this. In the article, drought experiments and different physiological data are missing although can be found in other article from the same authors (Fernández de Simón et al. 2021 Environ Exp Bot

186:104437 https://doi.org/10.1016/j.envexpbot.2021.104437) that complements the transcriptomic results.

Although it is mainly a descriptive work, it contributes with important information in a group of plant species, conifers, not very studied in comparison to angiosperm model plants such as Arabidopsis and rice. Especially considering the difficulties of working in conifers (long life cycles, big sizes, recalcitrant for transformation, without mutant collections, etc.) this work has an intrinsic value to improve our knowledge on plant biology from an evolutionary perspective. 